\title{
A feasibility study of the implementation of total quality management based on soft factor
}

\author{
Arash Shahin, Reza Dabestani \\ University of Isfahan (IRAN) \\ arashshabin@,hotmail.com; reza.dabestani@gmail.com
}

Received May 2010

Accepted January 2011

\section{Abstract:}

Purpose: The aim of this paper is to examine the feasibility of implementing TQM based on soft factors, which can influence the successful implementation of TQM.

Design/methodology/approach: A framework has been developed for the TQM soft factors based on literature review and respectively, questionnaires which are directly related to the addressed factors have been designed and distributed to the employees of an engineering service company as the main enablers of improving the effectiveness of TQM.

Findings: The findings imply that committed leadership, closer customer relationship, benchmarking and process improvement have the most correlations amongst the TQM soft factors. Training is the only factor which is not correlated to other soft factors. Leadership has also the highest value among the soft factors.

Research limitations/implications: The proposed framework is costly and time consuming due to the large number of questions it holds. In this study, it is assumed that sub factors have the same importance. But there is a possibility in which these subdivisions do not have the same relative importance weight. The study is also limited to one company and therefore, the findings should not be generalized. 
Practical implications: The proposed TQM soft factors framework can be useful for those organizations which consider TQM as an integrated quality management system as the major foundation for achievement of competitive advantage.

Originality/value: A comprehensive framework for TQM soft factors has been presented since it involves almost all of the soft factors addressed in the literature.

Keywords: total quality management, soft factors, framework, feasibility

\section{Introduction}

In 1980s, among practitioners, scholars and consulters of quality management, a new concept evolved under the name of Total Quality Management (TQM). The concept was strongly influenced by the experience of high-quality products from Japanese manufactures and by what had been learned about Japanese approaches to quality management (Zandin, 2001). TQM is an approach for continuously improving the quality of goods and services delivered through the participation of individuals at all levels of an organization (Pfau, 1989). TQM is more than a program; it is a way of business management for the whole organization. It is a holistic corporate philosophy including three fundamental principles of 'Total' as participation of every person and every department; 'Quality' as meeting customer needs and expectations; and 'Management' as enabling conditions for total quality (Whyte \& Witcher, 1992). Thus, TQM is defined as a comprehensive management philosophy which provides continuous improvement to all functions of an organization, and it is achieved when the subject of total quality is utilized from the acquisition of resources to customer service (Kaynak, 2003).

TQM practices have been published extensively in measurement studies as well as in the studies that the relationship of TQM practices with various dependent variables has been investigated. TQM emphasizes that customer requirements and business goals are inseparable. It affirms an integrated management approach based on a set of techniques to achieve this objective. It requires cooperation among every part and demands fundamental changes in every aspect of the organization. It also requires continuous improvement not only in products/services 
quality but also in all operations for creating an organizational quality culture (Yusuf et al., 2007). It is important to establish a positive TQM environment in the whole organization in order to implement TQM. If every department and individual understands the needs, process and benefits of TQM, employees will accept the TQM philosophy and as a result will do their job more effectively (Yusuf et al. 2007).

During the past 20 years, many authors have focused on the TQM factors and its dimensions. Ross (1993) explained TQM as a set of practices, continuous improvement, meeting customers' requirements, reducing rework, increased employee involvement and teamwork, process redesign, competitive benchmarking, team-based problem-solving, constant measurement of results, and closer relationships with suppliers. In this respect, several researchers have suggested different soft and hard factors for TQM. Hard factors are related to the techniques and tools such as statistical process control and problem solving methods while the soft factors refer to the "management" part of the TQM which involves people, culture and improvement.

Powell (1995) suggested 12 factors for TQM programs as it is shown in appendix A. Rahman and Bullock (2005) proposed a logical approach to study the soft TQM, hard TQM and organizational performance relationships. Al-Marri et al. (2007) found 16 factors as critical in successful implementation of TQM in a service industry. They include top management support, strategy, continuous improvement, benchmarking, customer focus, quality department, quality system, human resource management, recognition and reward, problem analysis, quality service technologies, service design, employees, services capes, service culture and social responsibility. As it was mentioned earlier, the soft dimensions of TQM refer to the management perspective of TQM practices. In the Powell's framework, flexible manufacturing and measurement are related to the hard aspects and the other factors refer to the soft aspects.

The purpose of this paper is to propose and examine a comprehensive framework for TQM soft factors. The proposed model is examined in an engineering service company located in Isfahan. For this purpose and prior to describing the new methodology, the TQM philosophy is divided into two dimensions as hard and soft. Then, elements of soft factors which affect the implementation of TQM are 
introduced. In the case study, correlation analysis is used to find interrelationships among TQM soft factors, to prioritize the addressed factors and to investigate feasibility implementation of TQM.

\section{TQM soft factors}

Hard TQM refers to a set of techniques and tools such as analyzing quality process, statistical process control, problem solving tools and just-in-time control used to continually improve quality while soft TQM deals with the management concepts. This dimension of TQM is more related to the word "management" which involves a set of principles as people, culture and improvement. To implement TQM effectively, organizations should pay more attention to the soft dimensions. TQM soft factors and their elaboration are as follows:

\section{1) Committed Leadership}

Management leadership is an important factor in TQM implementation because it improves performance through influencing other TQM practices (Wilson \& Collier, 2000). The lack of commitment in the top management levels may lead to some problems in the process of implementing TQM. Top management is completely involved in implementing and stimulating the TQM approach. Leadership is also responsible for the product and service which are offered (Gonzalez-Benito \& Martinez-Lorente, 1999). Successful implementation of TQM requires effective changes in an organization's culture and it is somehow impossible without management leadership (Ho et al., 1999). In a TQM process, effective leadership should develop a clear mission statement and then build up suitable strategies in order to support the mission. The top management needs to identify the critical success factors and to review the management structure. Leadership must ensure that the principles of quality management are implemented continually (Yusuf et al., 2007). The four distinctive ways that top management can support TQM implementation include allocating budgets and resources; control through visibility; monitoring progress; and planning for change (Motwani, 2001).

2) Adoption and Communication of TQM

Communication is the most difficult subject, especially in the business. Workers usually complain that they are not part of it (Jefferson, 2002). Communication also 
plays a vital role in efficient producing of high quality products. The misunderstanding of procedures and instructions may negatively influence a production system. Written instruction for quality improvement may not be implemented, if communication amongst employee does not exist effectively (Aly \& Schloss, 2003). In general, it is the most important issue that occurs. Data indicates that perceptions of open communication contribute to employees' feelings of satisfaction with and commitment to the organizations and managers they work for. More open communication is also the result of TQM's emphasis on customer satisfaction and better relationships with suppliers. Communication issues exist both within organizations and between organizations. The first one refers to internal or intra-organizational communication issues, primarily those involving communication between employees or between employees and management. The latter involves communication between a given organization and its suppliers and customers which were called external communication (J efferson, 2002).

\section{3) Closer Customer Relationship}

In TQM, a 'customer' is more than simply one who is external to the business. It also includes the person in another department, or the person next in line, who is called the internal customer. These people directly or indirectly relate and cooperate with each other to establish a quality chain. Every employee is a part of the chain, from supplier to external customer, including both line and support functions (Lindborg, 2003). Therefore, those employees who do not have direct contact with outside customers are encouraged to view their colleagues as internal customers and to meet their requirements. For continuous improvement, customers' requirements must be consistently measured and satisfied. The company should be organized to obtain the necessary information for the identification of customer requirements and to obtain reliable and fast feedback on the quality levels of currently available products/services (Forza \& Filippini, 1998). The needs of customers' satisfaction should be considered by all employees. A number of mechanisms have been analyzed by specialist to recognize the requirements and levels of customers' satisfaction (Gonzalez-Benito \& MartinezLorente, 1999). Methods such as market research, enquiring sales staff, and comparing competitors can be used to collect information. All of these procedures are implemented to achieve customer satisfaction. The relevance of customer satisfaction in the quality management literature is apparent. The measurement of 
customer satisfaction often has been based on a customer's perception of the quality of products and services (Anderson et al., 1994). In addition to the principles of continuous improvement and teamwork, customer satisfaction provides both the impetus for instituting and the standard for evaluating total quality initiatives. Three practices are identified by Dean and Bowen (1994) as instrumented in providing customer satisfaction as direct contact between product and/or service providers and their customers; the collection of specific information about customer requirements; and the inclusion of information provided by customers in the design and delivery of products and/or services (J efferson, 2002).

\section{4) Closer Supplier Relationship}

Some of the reasons for many organizations which try to link their suppliers' processes to their own system include poor quality costs due to the inferior quality of purchased goods; the Philosophy of Just in Time; and the necessity of having relationships with committed suppliers (Bergman \& Klefsjo, 2003). It is hard for companies to develop the level of creditability and trust needed to establish tight working relationships. Thus companies should use some tools, techniques and systems to make a suitable relationship with suppliers. Some of these systems include 'procurement Systems'; 'advanced planning and scheduling'; and 'transportation planning systems' (Hugos, 2003). The focus of procurement systems is on the procurement activities that take place between a company and its suppliers. The purpose of these systems is to streamline the procurement process and to make it more efficient. Such systems typically replace supplier catalogs with a product database that contains all the needed information about products the company buys. They also keep track of part numbers, prices, purchasing histories and supplier performance. Procurement systems allow company to compare the price and performance capabilities of different suppliers. In this way, the best suppliers are identified so that relationship can be established with these suppliers and prices negotiated. The routine transactions that occur in the purchasing process can then be largely automated (Hugos, 2003). Advanced Planning and Scheduling known as APS systems, are highly analytical applications that their purpose is to assess plant capacity, material availability, and customer demand. These systems then produce schedules for what to make, in which plant and at what time. The calculation of APS systems is based on the input of transaction level data that is extracted from 'Enterprise Resource Planning (ERP)' 
or legacy transaction processing systems. Linear programming techniques and other sophisticated algorithms can be used to create recommended schedules (Hugos, 2003). Transportation Planning Systems are systems that calculate the quantity of materials that should be brought to certain locations at certain times. The systems enable people to compare different modes of transportation, different routes, and different carriers. Vendors can provide the data that is needed by these systems, such as mileage, fuel costs, and shipping tariffs (Hugos, 2003).

\section{5) Benchmarking}

Benchmarking is a continuous process of comparing an organization's products, services and processes against those of its best competitors or those of organizations renowned as world class or industry leaders. In many companies, benchmarking is a key component of the TQM process, profitability and growth flow from a clear understanding of how the business is performing, not just against its previous accomplishment, but against the best competitors or world-class organizations (Ghobadian \& Woo, 1996). Benchmarking involves the identification of best practices among competitors in a given industry, among the recognized leaders in any industry, for the purpose of improving organizational processes and enhancing competitive position (Hackman \& Wageman, 1995; J efferson, 2002). It also includes measuring performance in the company which seeks improvement of activities. In the benchmarking process, managers should understand the reason of why their performance differs. An understanding of differences allows managers to organize their improvement efforts to meet the goal. Benchmarking is about setting goals and objectives and meeting them by improving processes (Besterfield et al., 1995). Benchmarking may contribute to an organization's ability to achieve competitive advantage by monitoring the best practices in the industry and diagnosing measure of performance. The typical classification of benchmarking which are pinpointed in the literature includes internal benchmarking; competitive benchmarking; functional benchmarking; and generic benchmarking (Carpinetti \& Melo, 2002).

\section{6) Increased Training}

Training of employees is crucial for building the 'human capital' of the organization. Training and education are essential to provide employees with new techniques and practices necessary to implement TQM successfully. Training and education are 
also necessary for teaching the TQM philosophy that requires permanent change in individual behaviors and attitudes and leads to strengthening the organization's culture (Shenawy et al., 2007). Training and education are primary levers for change, and they have significant influence on the change process (Buch \& Talentino, 2006). Training should focus on building quality skills with equal attention paid to behavioral skills and quality tools needed for change in performance management and recognition (Palo \& Padhi, 2005). Training includes explanation of overall company operations and product quality specifications. Specific measures for evaluating training include the time and money spent by organizations in training employees and management in quality principles, problem solving skills, and teamwork (Black \& Porter, 1996).

\section{7) Open Organization}

Powell (1995) considered empowered work teams as a major part of an open organization. Some also used 'teamwork' instead of the open organization concept. Teams should have authority to implement the changes and to motivate employees to participate into the change processes (Gonzalez-Benito \& Martinez-Lorente, 1999). The main issues influencing on team effectiveness in an open organization are diversity and cohesiveness (Jefferson, 2002). Diversity is generally considered as one of the sources of the fundamental advantage that teams offer compared to individual efforts (Rogelberg \& Rumery, 1996). One of the primary sources of TQM team diversity comes from the inclusion of front-line employees in decision making teams. Several researchers (Hackman \& Wageman, 1995) have argued that meeting between managers and workers is a crucial source of ideas about how to improve operations that directly impact the quality of outputs. The importance of diversity is directly related to the variety of perspectives that are included when teams are composed of members across the organization (Jefferson, 2002). Another consideration in terms of diversity is the formation of teams that include customers as well as product or service suppliers. Customers in this context include internal customers and external customers. Internal customer concept is coincident with the idea of cross-functional team membership (Hackman \& Wageman, 1995). External customers can provide an important source of information and a diverse set of perspectives which can be crucial to TQM effectiveness (J efferson, 2002). Cohesiveness between team members can be considered as an affinity for and degree of commitment to achieve organization's purposes (Langfred, 1998), group 
climate (cooperative or competitive) and the tensions and conflicts which are available among team members (Hare, 1994). Cohesiveness improves group productivity (Gully et al., 1995) and can cause higher individual performance (J efferson, 2002).

\section{8) Employee Empowerment}

Employee empowerment is an integral part of any successful quality improvement process which helps employees to make decisions about their own work and environment. This also encourages people to apply the most appropriate tools and techniques (McQuater et al., 1995). In general, empowerment is a core concept in a humanistic management movement that is distinguishable from the more mechanistic 'scientific management' traditions. According to the conceptual logic, people are the principle resource of organizations. Empowerment is a central concept in TQM that has been credited with making a major contribution to the Japanese revival and has been adopted with enthusiasm in other parts of the world (Lloyd et al., 1999). specific measures of employee empowerment include the degree to which cross-departmental and work teams are used; the extent of employee autonomy in decision making; the extent of employee interaction with customers; and the extent to which employee suggestion systems are being used (Powell, 1995).

\section{9) Zero-Defect Mentality}

Most authors endorse a 'zero defect' and a 'do it right the first time' attitude towards the quality program. Quality programs should measure the percentage or the number of parts that deviate from the acceptable items in order to prevent the recurrence of a defect (Motwani, 2001). Therefore, it requires that all the people attempt to enhance zero defect mentality approach in order to reduce inspection and waste (Yusuf et al., 2007). Some authors have stated the ways which encompass the 'zero-defect mentality' such as monitoring supplier quality levels, utilizing SPC to reduce process variability, and calculating the cost of quality (Powell, 1995). The cost of quality could include relevant changes in market share, warranty costs, inspection, rework and scrap costs. The cost of nonconforming raw materials could include lost revenue or productivity costs and would aid in vendor selection and certification (Motwani, 2001). 
10) Process Improvement

Process improvement is a key aspect in TQM programs (Sinclair \& Zairi, 1995). Process analysis has its primary objective, i.e., the reduction or elimination of variance, which Deming (1986) saw as the source of problems in providing quality products and services. A reduction in process variation leads to benefits such as increasing output uniformity, continual reduction of waste of staffing, machine time, and materials (Anderson et al., 1994). This factor emphasizes adding value to processes, increasing quality levels, and raising productivity per employee (Motwani, 2001) and contains improving work center methods and installing operator-controlled processes that lead to a lower unit cost, embracing kaizen (continuous improvement) philosophies, reducing the operator material handling duties, promoting a design for a manufacturing program, and achieving a compact process flow (Kasul \& Motwani, 1995a; Kasul \& Motwani, 1995b). Continuous improvement can be efficiently achieved in organizations only if a structured continuous improvement process is in place to guide managers (Sinclair \& Zairi, 1995).

\section{New methodology}

In this section, all the soft factors and the details of each factor are integrated in a proposed framework (Figure 1). This framework consists of two levels and encompasses all the management aspects of TQM philosophy. The first level refers to the TQM soft factors, while the second level contains the details of each factor. The second level determines the methods of measuring soft factors and the way of implementing TQM, successfully. Factors in the first level are derived from the Powell's TQM factors, while the sub-factors in the second level are gathered from a comprehensive review of several related textbooks and research journals reviewed in previous sections of this paper. In this study, a sample statistics process based on the TQM soft factors framework is utilized to examine the feasibility of implementing TQM in an organization. The factors of the proposed framework are used in designing a questionnaire for field study. 


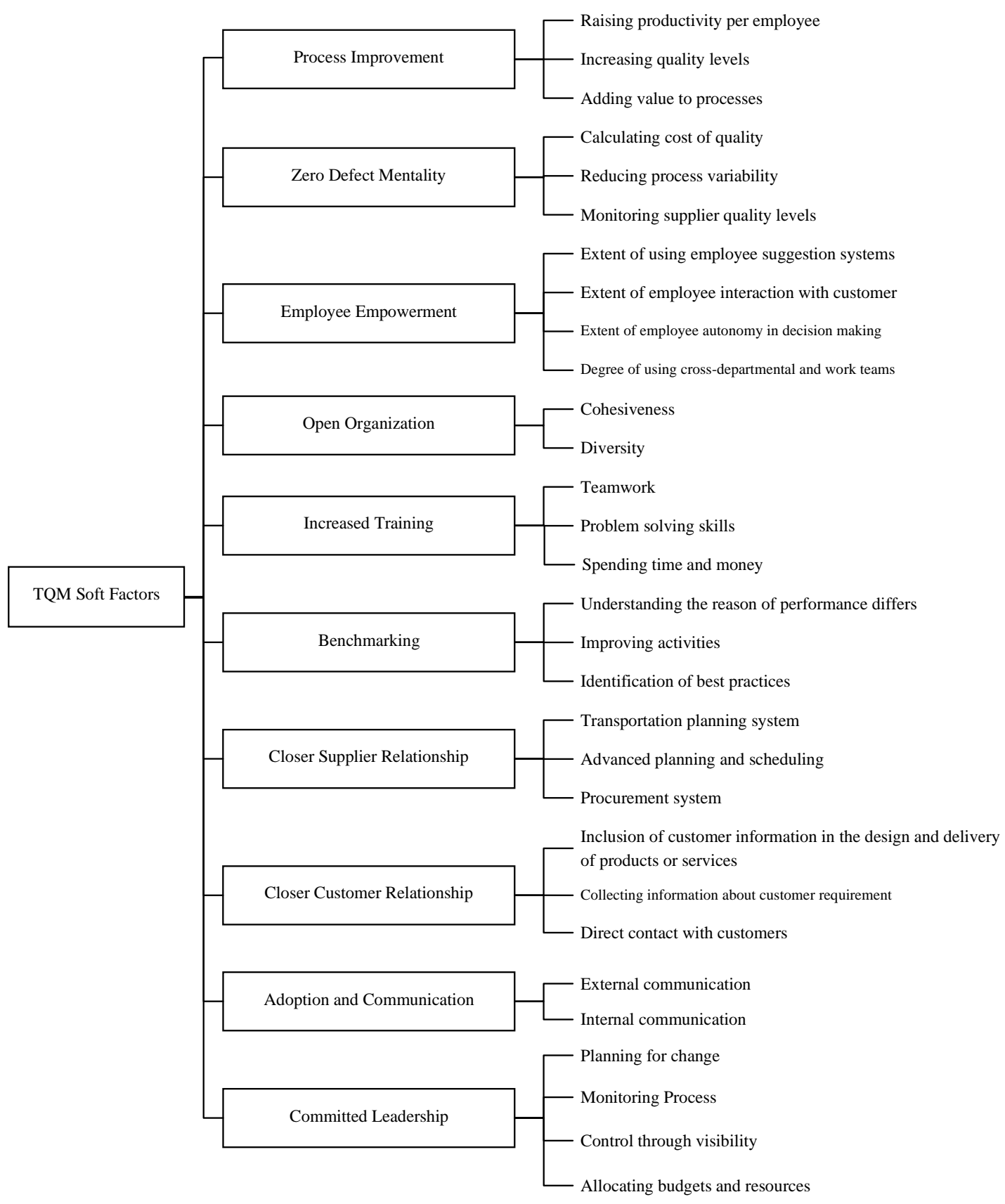

Figure 1. "The proposed framework of TQM soft factors".

It is important to note that the proposed model is verified using a survey on 14 experts including seven experts from universities and seven managers of nongovernmental organizations. Before the experts begin filling out the questionnaires, the definitions of the TQM soft factors and the reasons for their inclusion in model are clearly explained to each of them. In order to confirm the consistency of the 
experts' opinions on the corresponding results, the binomial test is used to test the null hypothesis of 'There are no differences among experts' opinions'. Each expert indicates his/her opinion by selecting 'Agree' (1) or 'Disagree' (0). The test proportion is assumed as 0.50 denoting that at least 50 percent of the experts are expected to agree on the model. The results are represented in Table 1. As it is clear, the significance levels are all smaller than 0.05 and the test proportion $(0.50)$ is less than the observed proportions. Therefore, it is concluded that the null hypothesis is rejected and there is difference among the experts' opinions. According to the 'agreed proportions', which are all greater than 0.80 , it is argued that the experts mostly agree on the proposed model with a confidence level of 0.95 .

\begin{tabular}{|c|c|c|c|c|}
\hline $\begin{array}{c}\text { Soft } \\
\text { factor }\end{array}$ & Agreed Proportion & Disagreed proportion & $\begin{array}{c}\text { Test } \\
\text { proportion }\end{array}$ & $\begin{array}{c}\text { Exact Sig. } \\
\text { (2-tailed) }\end{array}$ \\
\hline 1 & 0.81 & 0.19 & 0.50 & 0.021 \\
\hline 2 & 0.81 & 0.19 & 0.50 & 0.021 \\
\hline 3 & 0.81 & 0.19 & 0.50 & 0.021 \\
\hline 4 & 0.81 & 0.19 & 0.50 & 0.021 \\
\hline 5 & 0.88 & 0.13 & 0.50 & 0.004 \\
\hline 6 & 0.81 & 0.19 & 0.50 & 0.021 \\
\hline 7 & 0.88 & 0.13 & 0.50 & 0.004 \\
\hline 8 & 1.00 & 1.00 & 0.50 & 0.000 \\
\hline 9 & 0.88 & 0.13 & 0.50 & 0.004 \\
\hline 10 & 1.00 & 1.00 & 0.50 & 0.000 \\
\hline
\end{tabular}

Table 1. "The results of the binomial test".

\section{Case study}

The case study includes a sample of 66 employees who work in an engineering service company called Foolad Technique International Engineering Co. (FTIEC), which is located in Isfahan, Iran. FTIEC was established in 1991 based on a private enterprise system, followed by cooperation with skillful employees, attracting best graduates from universities in different fields. Accessibility to the scientific and technical information, cooperating with reliable and up-to-date international sources, using modern equipment in software and hardware technologies, handling huge civil and industrial projects lead to delivering appropriate and quality services to the customers by the company, supported by established Quality Management System in accordance with ISO9000-2000, Environment Management System (ISO 14001-2004), Occupation Health \& Safety Assessment Standard (OHSAS 180012007) and H.S.E Management System. 
A questionnaire including 30 questions is designed considering the soft factors addressed in Figure 1 . The questionnaire is submitted to the employees of the company. Employees are randomly selected from different departments of the central office of the company in Isfahan. Prior to distribution of the final questionnaires, the researchers checked the questions with a number of quality management experts and executives to find out whether the items are understandable, need improvement, etc. A five point Likert scale is considered as the answer options ( 1 as very low, 2 as low, 3 as moderate, 4 as high and 5 as very high). In the questionnaire, four questions are related to Committed Leadership, two questions to Adoption and Communication, four questions to Customer Relationship, three questions to Supplier Relationship, three questions to Benchmarking, three questions to Training, two questions to Open Organization, four questions to Employee Empowerment, three questions to Zero Defect Mentality and three questions to Process Improvement. 75 questionnaires are distributed in the company and 66 questionnaires are completed with the response rate 88 percent. Table 2 addresses the demographic characteristics of employees according to age, gender, education level, manager status, and tenure and experience.

\begin{tabular}{|c|c|c|c|c|c|}
\hline Factor & $\mathrm{N}$ & $\%$ & Factor & $\mathrm{N}$ & $\%$ \\
\hline \multicolumn{3}{|l|}{ Age } & \multicolumn{3}{|l|}{ Gender } \\
\hline 20 to 29 & 23 & 35 & Male & 30 & 45 \\
\hline 30 to 39 & 39 & 59 & Female & 36 & 55 \\
\hline 40 to 49 & 2 & 3 & \multicolumn{3}{|l|}{ Education Major } \\
\hline 50 to 59 & 2 & 3 & $\begin{array}{l}\text { Electronic } \\
\text { Engineering }\end{array}$ & 15 & 23 \\
\hline 60 and over & 0 & 0 & $\begin{array}{l}\text { Industrial } \\
\text { Engineering }\end{array}$ & 12 & 19 \\
\hline \multicolumn{3}{|c|}{ Tenure in present occupation } & Civil Engineering & & \\
\hline 1 year or less & 0 & 0 & $\begin{array}{l}\text { Mechanical } \\
\text { Engineering }\end{array}$ & 7 & 11 \\
\hline 1 to 5 years & 34 & 52 & Economics & 6 & 9 \\
\hline 5 to 10 years & 24 & 36 & Accounting & 4 & 6 \\
\hline 10 to 20 years & 8 & 12 & Material Engineering & 3 & 5 \\
\hline 20 and over & 0 & 0 & $\begin{array}{l}\text { Computer } \\
\text { Engineering }\end{array}$ & 3 & 5 \\
\hline \multicolumn{3}{|l|}{ Education Level } & Others & 6 & 9 \\
\hline High School or other & 0 & 0 & \multicolumn{3}{|l|}{ Manager Status } \\
\hline Diploma & 2 & 3 & Supervisor & 21 & 32 \\
\hline Associates & 4 & 6 & Non-Supervisor & 45 & 68 \\
\hline Bachelor & 39 & 5 & \\
\hline Master & 19 & 2 & & & \\
\hline Doctorate & 2 & 3 & & & \\
\hline
\end{tabular}

Table 2. "Sample demographic characteristics". 
Subsequently, statistical analyses are undertaken to examine the data. As it is clear, majority of the sample of respondents contains young people (95 percent less than 39 years old. In this category, 35 percent of respondents are between 20 and 29 years old and 59 percent of them are between 30 and 39 years old. 52 percent of employees have less than five years of tenure in their present occupations. All of the employees have more than one year and less than 20 years of tenure in their present job. Most of the employees (59 percent) have bachelor degree. The considerable point in this study is that 32 percent of employees have postgraduate degree and only three percent of them do not have academic education. This advantage may simplify the process of implementing management and engineering systems in the organization. The educated employee might also have a better understanding of the complicated situation and unstable condition. The titles of the survey respondents include vice president, general manager, executive manager, quality manager, operations manager, project manager, engineers, specialist, etc.

\section{Findings}

The findings of this research can help managers of the company to better understand the required condition for implementing TQM. The values in Table 3 denote that committed leadership has the highest value amongst TQM soft factors. The other factors also have higher values than average. Also, benchmarking and training have the lowest values amongst the TQM soft factors.

The Cronbach's Alpha of the data is calculated and denotes a reliability level of 0.833 which is satisfactory. The Pearson correlation test is also performed and the results are presented in Table 4. As it is shown, there are correlations amongst all the TQM soft factors but the significant correlations are just related to a few of the soft factors. As it is illustrated, committed leadership, closer customer relationship, benchmarking and process improvement have the highest correlation with other soft factors, while training has no significant correlation with soft factors. As a rule, correlation values of 0.5 and higher are considered as significant. The highest correlation value (i.e. 0.628) is referred to open organization and process improvement, while the lowest value is related to closer supplier relationship and zero defect mentality. 


\begin{tabular}{|c|l|c|c|c|l|c|c|}
\hline No. & \multicolumn{1}{|c|}{ I tem } & Mean & Std. Dev. & No. & \multicolumn{1}{|c|}{ Item } & Mean & Std. Dev. \\
\hline 1 & $\begin{array}{l}\text { Committed } \\
\text { Leadership }\end{array}$ & 4.197 & 0.5876 & 6 & $\begin{array}{l}\text { Increased } \\
\text { Training }\end{array}$ & 3.394 & 0.6990 \\
\hline 2 & $\begin{array}{l}\text { Adoption and } \\
\text { Communication }\end{array}$ & 3.682 & 0.6363 & 7 & $\begin{array}{l}\text { Open } \\
\text { Organization }\end{array}$ & 3.621 & 0.7393 \\
\hline 3 & $\begin{array}{l}\text { Closer Customer } \\
\text { Relationship }\end{array}$ & 3.758 & 0.7857 & 8 & $\begin{array}{l}\text { Employee } \\
\text { Empowerment }\end{array}$ & 3.712 & 0.5755 \\
\hline 4 & $\begin{array}{l}\text { Closer Supplier } \\
\text { Relationship }\end{array}$ & 3.682 & 0.6363 & 9 & $\begin{array}{l}\text { Zero Defect } \\
\text { Mentality }\end{array}$ & 3.576 & 0.5834 \\
\hline 5 & Benchmarking & 3.394 & 0.7266 & 10 & $\begin{array}{l}\text { Process } \\
\text { Improvement }\end{array}$ & 3.742 & 0.6155 \\
\hline
\end{tabular}

Table 3. "Mean and Std. deviation values of TQM soft factors".

\begin{tabular}{|c|c|c|c|c|c|c|c|c|c|c|c|}
\hline No. & $\begin{array}{l}\text { TQM Soft } \\
\text { Factors }\end{array}$ & 1 & 2 & 3 & 4 & 5 & 6 & 7 & 8 & 9 & 10 \\
\hline 1 & $\begin{array}{l}\text { Committed } \\
\text { Leadership }\end{array}$ & 1 & $0.458^{* *}$ & 0.572 & 0.499 & $0.509^{* *}$ & 0.445 & $0.422^{* *}$ & $0.352^{* *}$ & $0.517^{* *}$ & $0.483^{* *}$ \\
\hline 2 & $\begin{array}{l}\text { Adoption and } \\
\text { Communication }\end{array}$ & & 1 & $0.490^{* *}$ & 0.392 & $0.543^{* *}$ & 0.321 & $0.590^{* *}$ & $0.418^{* *}$ & $0.501^{* *}$ & $0.652^{* *}$ \\
\hline 3 & $\begin{array}{l}\text { Closer Customer } \\
\text { Relationship }\end{array}$ & & & 1 & 0.336 & $0.510^{* *}$ & 0.401 & $0.449^{* *}$ & $0.354^{* *}$ & $0.578^{* *}$ & $0.537^{* *}$ \\
\hline 4 & $\begin{array}{l}\text { Closer Supplier } \\
\text { Relationship }\end{array}$ & & & & 1 & $0.310^{*}$ & 0.286 & $0.329^{* *}$ & $0.376^{* *}$ & $0.252^{*}$ & $0.377^{* *}$ \\
\hline 5 & Benchmarking & & & & & 1 & 0.372 & $0.402^{* *}$ & $0.477^{* *}$ & $0.366^{* *}$ & $0.502^{* *}$ \\
\hline 6 & $\begin{array}{l}\text { Increased } \\
\text { Training }\end{array}$ & & & & & & 1 & $0.353^{* *}$ & $0.401^{* *}$ & $0.416^{* *}$ & $0.490^{* *}$ \\
\hline 7 & $\begin{array}{l}\text { Open } \\
\text { Organization }\end{array}$ & & & & & & & 1 & $0.427^{* *}$ & $0.406^{* *}$ & $0.628^{* *}$ \\
\hline 8 & $\begin{array}{l}\text { Employee } \\
\text { Empowerment }\end{array}$ & & & & & & & & 1 & $0.410^{* *}$ & $0.352^{* *}$ \\
\hline 9 & $\begin{array}{l}\text { Zero Defect } \\
\text { Mentality }\end{array}$ & & & & & & & & & 1 & $0.462^{* *}$ \\
\hline 10 & $\begin{array}{l}\text { Process } \\
\text { Improvement }\end{array}$ & & & & & & & & & & 1 \\
\hline
\end{tabular}

*Significant at $0.05, * *$ Significant at 0.01

Table 4. "Two tailed Pearson correlation test of the TQM soft factors".

\section{Discussion}

The results suggest that in general, the TQM soft factors are significantly related to each other. Four out of 10 TQM soft factors have positive correlation with other factors. They include committed leadership, closer customer relationship, benchmarking and process improvement. This finding encourages the company to emphasize on these factors in order to provide the suitable condition for successful implementation of TQM. The lowest value in this study was referred to closer supplier relationship and zero defect mentality. It is important to note that factors such as supplier relationship can be more relevant to manufacturing firms than service organizations. Since the company provides engineering services to customers, the suppliers are not the main factors which influence services and 
internal activities of the employees are the main reasons of delivering suitable services. Another important result is related to training as a vital factor. This factor has no significant correlation with other soft factors. It seems that this result may be related to the education level of the employees in organization. Based on the collected data, 91 percent of the employees have bachelor, master and doctorate degrees. So, the employees are somehow socialized and trained before entering to the company. The results imply that committed leadership is a significant factor and has the highest correlation with customer relationship, supplier relationships, benchmarking and zero defect mentality factors. Hence, it can be concluded that organization can improve the mentioned factors through concentrating on leadership. This factor might be improved by the means of the sub-factors of leadership presented in the comprehensive framework. Training with the lowest value of 3.394 should be improved through the factors in the second level of framework including teamwork, problem solving skills and spending time and money. This factor does not have significant correlation with other soft factor. Benchmarking has also the lowest value of 3.394 amongst the TQM soft factors. This factor can be improved through the sub factors in the second level of framework and other correlated factors. The findings of this study are compatible with the study of Warwood and Roberts (2004). Based on this research, leadership/senior management commitment and employee involvement are effective factors in TQM implementation. Deming (2000) and Kaynak (2003) also believed that top management is one of the major prerequisites of successful TQM implementation. Closer customer relationship is referred to as a vital factor in TQM programs and is correlated with other dimensions of the organization. This subject has been proved in the literature. Chong and Rundos (2004) and Taylor and Wright (2003) stated that customer focus is the most fundamental factor in TQM.

\section{Conclusions}

In this study, a comprehensive framework was proposed which addresses the TQM soft factors. The framework was also examined using a survey in an engineering service company. The framework included 10 major factors and 30 sub-factors. The proposed framework is comprehensive since it involves almost all of the soft factors addressed in the literature. The factors are apparent in every industry, while their detail and importance may differ. Considering the findings of the case study, the most important factors include committed leadership, closer customer 
relationship, benchmarking and process improvement. These factors have more relationship with other soft factors. Therefore, it is recommended that companies consider these factors in the process of implementing TQM. Closer supplier relationship is also recognized as an ineffective factors on the zero defect mentality if the supplier directly does not influence the delivered services. There is also a high correlation between adoption and communication and process improvement. The differences are due to the organizational structure, culture or the sensitivity of processes. Therefore, examination of the framework in different industries provides great opportunities for future studies. This framework provides a suitable structure for hierarchical analysis; therefore, approaches such as multi-criteria decision making (e.g., AHP, ANP) can be used to prioritize the soft factors. Due to its comprehensiveness, the proposed framework is suggested to organizations which consider TQM as an integrated quality management system as the major foundation for achievement of competitive advantage. The soft factors pinpoint to the fact that a successful implementation of TQM requires all aspects of TQM including a new quality culture in the organization. To be successful, top management should focus on maximizing performance through improving systems and processes together with other requirements which were addressed in the framework. The proposed framework of soft factors seems comprehensive, comparing to the literature, although it is costly and time consuming due to the large number of questions it holds. All similar researches, because of being survey based and conceptual, suffer the same problem. In this study, it was assumed that sub factors have the same importance; but it is possible that these subdivisions become not equal in terms of relative importance weight. The study is also limited to one company and therefore, the findings should not be generalized.

\section{Appendix A: The 12 TQM factors. Source: Powell (1995)}

1. Committed leadership: a near-evangelical, unwavering, long-term commitment by top managers to the philosophy, usually under a name something like TQM, Continuous Improvement ( $\mathrm{Cl}$ ), or Quality Improvement (QI).

2. Adoption and communication of TQM: using tools like the mission statement, and themes or slogans. 
3. Closer customer relationships: determining customers' (both inside and outside the firm) requirements, then meeting those requirements no matter what it takes.

4. Closer supplier relationships: working closely and cooperatively with suppliers (often sole sourcing key components), ensuring they provide inputs that conform to customers' end-use requirements.

5. Benchmarking: researching and observing best competitive practices.

6. Increased training: usually includes TQM principles, team skills, and problemsolving.

7. Open organization: lean staff, empowered work teams, open horizontal communications, and a relaxation of traditional hierarchy.

8. Employee empowerment: increased employee involvement in design and planning, and greater autonomy in decision-making.

9. Zero-defects mentality: a system in place to spot defects as they occur, rather than through inspection and rework.

10. Flexible manufacturing: (applicable only to manufacturers) can include just-intime inventory, cellular manufacturing, design for manufacturability (DFM), statistical process control (SPC), and design of experiments (DOE).

11. Process improvement: reduced waste and cycle times in all areas through cross departmental process analysis.

12. Measurement: goal-orientation and zeal for data, with constant performance measurement often using statistical methods.

\section{Acknowledgment}

The authors would like to acknowledge the collaboration of Dr. Hadi Shirouyehzad for providing assistance in data analysis. 


\section{References}

Al-Marri, Kh., Baheeg Ahmed, A.M.M., \& Zairi, M. (2007). Excellence in service: an empirical study of the UAE banking sector. International Journal of Quality and Reliability, 24(2), 164-176.

\section{doi: $10.1108 / 02656710710722275$}

Aly, N., \& Schloss, D. (2003). Assessing quality management systems of Mexico's maquiladoras. The TQM Magazine, 15(1), 30-36.

doi: $10.1108 / 09544780310454420$

Anderson, J.C., Rungtusanatham, M., \& Schroeder, R.G. (1994). A theory of quality management underlying the Deming management method. Academy of Management Review, 19(3), 472-509.

doi: 10.5465/AMR. 1994.9412271808

Bergman, B., \& Klefsjo, B. (2003). Quality from Customer Needs to Customer Satisfaction. 2nd Edition. Lund: Studentlitteratur.

Besterfield D.H., Besrerfield-Michna, C., Besterfield, G.H., \& Besterfield-Sacre, M. (1995). Total Quality Management. New Jeresy: Prentice-Hall, Inc.

Black, S., \& Porter, L. (1996). Identification of the critical factors of TQM. Decision Sciences, 27(1), 1-21.

doi: 10.1111/j.1540-5915.1996.tb00841.x

Buch, K.K., \& Tolentino, A. (2006). Employee expectancies for six sigma success. Leadership \& Organization Development Journal, 27(1), 28-37. doi: $10.1108 / 01437730610641340$

Chong, V.K., \& Rundus, M.J. (2004). Total quality management, market competition and organizational performance. The British Accounting Review, 36(2), 155-172.

doi: 10.1016/j.bar.2003.10.006

Carpinetti, L.C.R., \& Melo, A.M.D. (2002). What to benchmark? A systematic approach and cases. Benchmarking: An International J ournal, 9(3), 244-255. 
Dean, J.W., \& Bowen, D.E. (1994). Management theory and total quality: Improving research and practice through theory development. Academy of Management Review, 19(3), 392-418.

doi: 10.5465/AMR. 1994.9412271803

Deming, W.E. (1986). Out of the Crisis. Cambridge, MA: MIT Center for Advanced Engineering Study.

Deming, W.E. (2000). The New Economics for Industry. Cambridge, MA: Government Education, MIT Press.

Forza, C., \& Filippini, R. (1998). TQM impact on quality conformance and customer satisfaction: a casual model. International Journal of Production Economics, 55(1), 1-20.

doi: $10.1016 / 50925-5273(98) 00007-3$

Ghobadian A., \& Woo, H.S. (1996). Characteristics, benefits and shortcomings of four major quality awards. International Journal of Quality \& Reliability Management, 13(2), 10-44.

doi: $10.1108 / 02656719610109999$

Gonzalez-Benito, J., \& Martinez-Lorente A.R. (1999). Business process reengineering to Total Quality Management; An examination of the issues. Business Process Management J ournal, 5(4), 345-358.

doi: $10.1108 / 14637159910297385$

Gully, S., Devine, D., \& Whitney, D. (1995). A meta-analysis of cohesion and performance: Effect of level of analysis and task interdependence. Small Group Research, 26(4), 497-520.

doi: $10.1177 / 1046496495264003$

Hackman, J.R., \& Wageman, R. (1995). Total quality management: Empirical, conceptual, and practical issues. Administrative Science Quarterly, 40(2), 309342.

doi: $10.2307 / 2393640$ 
Hare, A. (1994). Type of roles in small groups: A bit of history and a current perspective. Small Group Research, 25(3), 433-448.

doi: $10.1177 / 1046496494253005$

Ho, D.C.K., Duffy, V.G., \& Shih, H.M. (1999). An empirical analysis of effective TQM implementation in the Hong Kong electronics manufacturing industry. Human Factors \& Ergonomics in Manufacturing, 9(1), 1-25.

doi: 10.1002/(SICI)1520-6564(199924)9: 1<1: :AID-HFM1>3.3.CO;2-C doi: 10.1002/(SICI)1520-6564(199924)9:1<1::AID-HFM1>3.0.CO;2-L

Hugos, M. (2003). Essentials of Supply Chain Management. New Jersey: John Wiley.

Jefferson, R.W. (2002). Total Quality Management: an organizational communication analysis. Doctorate Theses, Austin: University of Texas.

Kasul, R., \& Motwani, J. (1995a). Performance measurements in world-class operations. Benchmarking for Quality Management \& Technology, 2(2), 20-36.

Kasul, R., \& Motwani, J. (1995b). Total quality management in manufacturing: Thematic factor Assessment. International Journal of Quality \& Reliability Management, 2(3), 57-76.

doi: $10.1108 / 02656719510084781$

Kaynak, H. (2003). The relationship between total quality management practices and their effects on firm performance. Journal of Operations Management, 21(4), 405-435.

doi: $10.1016 / 50272-6963(03) 00004-4$

Langfred, C. (1998). Is group cohesiveness a double-edged sword? Small Group Research, 29(1), 124-143.

doi: $10.1177 / 1046496498291005$

Lindborg, H. (2003). The shift to customer focus. Quality Progress, 36(3), 84-85.

Lloyd, P., Braithwaite, J., \& Southon, G. (1999). Empowerment and the performance of health services. Journal of Management in Medicine, 13(2), 83-94. doi: $10.1108 / 02689239910263163$ 
McQuater, R.E., Scurr, C.H., Dale, B.G., \& Hillman, P.G. (1995). Using quality tools and techniques successfully. The TQM Magazine, 7(6), 37-42.

doi: $10.1108 / 09544789510103761$

Motwani, J. (2001). Critical factors and performance measures of TQM. The TQM Magazine, 13(4), 292-300.

doi: $10.1108 / 13683040010362300$

Palo, S., \& Padhi, N. (2005). How HR professionals drive TQM: a case study in an Indian organization. The TQM Magazine, 17(5), 467-485.

doi: $10.1108 / 09544780510615960$

Pfau, L.D. (1989). Total Quality Management gives companies a way to enhance position in global marketplace. Industrial Engineering, 21(4), 17-21.

Powell, T.C. (1995). Total quality management as competitive advantage: A review and empirical study. Strategic Management Study, 16(11), 15-37.

doi: $10.1002 / \mathrm{smj} .4250160105$

Rahman, S., \& Bullock, Ph. (2005). Soft TQM, hard TQM, and organizational performance relationships: an empirical investigation. OMEGA, 33(1), 73-83. doi: 10.1016/j.omega.2004.03.008

Rogelberg, S., \& Rumery, S. (1996). Gender Diversity, team decision quality, time on task, and interpersonal cohesion. Small Group Research, 27(1), 79-90. doi: $10.1177 / 1046496496271004$

Ross, J. (1993). Total Quality Management: Text, Cases and Readings. Delray Beach, Florida: Lucie Press.

Shenawy, E.E., Baker, T., \& Lemak, D.J. (2007). A meta-analysis of the effect of TQM on competitive advantage. International Journal of Quality \& Reliability Management, 24(5), 442-471.

doi: $10.1108 / 02656710710748349$

Sinclair, D., \& Zairi, M. (1995). Effective process management through performance measurement, Part II - benchmarking total quality based performance measurement for best practice. Business Process Re-engineering \& Management Journal, 1(2), 58-72. 
Taylor, W.A., \& Wright, G.H. (2003). The impact of senior managers' commitment on the success of TQM programmes: An empirical study. International Journal of Manpower, 24(5), 535-550.

doi: $10.1108 / 01437720310491071$

Warwood, S.G., \& Roberts, P.A.B. (2004). A survey of TQM success factors in the UK. Total Quality Management, 15(8), 1109-1117.

Whyte, J., \& Witcher, B. (1992). The Adoption of Total Quality Management in Northern England. Durham: Durham University Business School.

Wilson, D.D., \& Collier, D.A. (2000). An empirical investigation of the Malcolm Baldrige National Quality award causal model. Decision Sciences, 31(2), 361-390. doi: 10.1111/j.1540-5915.2000.tb01627.x

Yusuf, Y., Gunasekaran, A., \& Dan, D. (2007). Implementation of TQM in China and Organisation Performance: An Empirical Investigation. Total Quality Management \& Business Excellence, 18(5), 509-530.

doi: $10.1080 / 14783360701239982$

Zandin, K.B. (2001). Maynard's Industrial Engineering Handbook. Fifth Edition. New York, NY: McGraw-Hill.

Journal of Industrial Engineering and Management, 2011 (www.jiem.org)

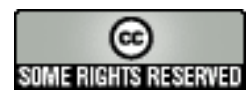

Article's contents are provided on a Attribution-Non Commercial 3.0 Creative commons license. Readers are allowed to copy, distribute and communicate article's contents, provided the author's and Journal of Industrial Engineering and Management's names are included. It must not be used for commercial purposes. To see the complete license contents, please visit http://creativecommons.org/licenses/by-nc/3.0/. 